\title{
Neonatal respiratory support strategies for the management of extremely low gestational age infants: an Italian survey
}

\author{
Flavia Petrillo ${ }^{1}$, Camilla Gizzi ${ }^{2}$, Gianfranco Maffei ${ }^{3}$, Piero G. Matassa ${ }^{4}$, Maria Luisa Ventura ${ }^{5}$, Cinzia Ricci, \\ Roberta Pastorino ${ }^{7}$, Giovanni Vento ${ }^{6^{*}} \mathbb{D}$, on Behalf of Neonatal Pneumology Study Group Italian Society of \\ Neonatology
}

\begin{abstract}
Background: We aimed to survey Delivery Room and Neonatal Intensive Care Unit (NICU) respiratory strategies dedicated to the extremely low gestational age newborn (ELGAN - GA $<28$ wks) in Italy.

Methods: A questionnaire was sent to 113 Italian level III centres. A lead physician and a nurse with expertise in mechanical ventilation (MV) were identified in each unit to answer. Information about those aspects of ventilatory support considered by center's staff as needing improvement was also collected.

Results: A 100\% response rate was obtained. In the Delivery Room, sustained lung inflation was performed in 74. $8 \%$ of centres, and $89.2 \%$ used NCPAP. For ELGANs who need invasive MV, conventional MV was the most used strategy. Volume-targeted ventilation and High-frequency oscillatory ventilation (HFOV) were considered as primary mode in $<30 \%$ of centres. Among non-invasive strategies, NCPAP was the most utilized, followed by BiPAP, Highflow nasal cannula and nasal intermittent positive pressure ventilation. Nurses more commonly recorded in the nursing charts the ventilator's setting parameters rather than measured ones. HFOV and non-invasive ventilation were the most quoted aspects of neonatal ventilation felt as to be improved.
\end{abstract}

Conclusion: The routine respiratory support practices in Italy showed marked variations among units. Focused interventions are largely required to improve clinical practice.

Keywords: Survey, Preterm infants, Mechanical ventilation, Non-invasive respiratory support, Training

\section{Background}

Extremely low gestational age newborns (ELGANs), born before 28 weeks of gestation, represent a particularly fragile category of patients, requiring a challenging, careful and multidisciplinary management. Despite the significant progress of the available technologies and modern devices observed in the last few years, ELGANs remain at high risk of developing pulmonary sequelae, especially bronchopulmonary dysplasia (BPD). BPD is a multifactorial disease related to different factors, being ventilator induced lung injury (VILI) the main one.

\footnotetext{
*Correspondence: giovanni.vento@unicatt.it

${ }^{6}$ Department of Woman and Child Health and Public Health, Division of Neonatology, Fondazione Policlinico Universitario A. Gemelli IRCCS Università Cattolica del Sacro Cuore, Rome, Italy

Full list of author information is available at the end of the article
}

Recent evidences indicate that some ventilatory approaches, such as the "open lung strategy" and the volume-targeted ventilation, are able to reduce VILI and to improve extremely preterm infants respiratory outcomes [1-4]. Nevertheless, there is still a huge heterogeneity among different neonatal intensive care units (NICUs) regarding adopted ventilation strategies and devices. The Working Group on Neonatal Pneumology of the Italian Society of Neonatology strongly promotes the implementation of Best Practice Guidelines on ventilation around the country organizing focused interventions, such theoretical/practical courses and residential trainings, with the aim to meet physicians' and nurses' upgrading needs and to improve outcomes in this particular category of newborn babies. Indeed, it has been shown that guidelines

(c) The Author(s). 2019 Open Access This article is distributed under the terms of the Creative Commons Attribution 4.0 International License (http://creativecommons.org/licenses/by/4.0/), which permits unrestricted use, distribution, and 
implementation is associated with a significant improvement of infants' respiratory management [5-7].

In 2014, our Working Group performed a national survey among Italian tertiary centres in order to 1) verify the current practice of neonatal respiratory support in DR and NICU in Italy for ELGANs, and 2) gather information about Italian tertiary centres' staff upgrading needs, and 3) plan, accordingly, tailored residential training or courses on those ventilation strategies considered to be improved in each unit.

\section{Methods}

The survey was conducted between May and September 2014, data referring to 2013. Centers' participation was voluntary. A lead physician with expertise in mechanical ventilation was identified in each unit by our Working Group who in turn identified an expert nurse. Two different questionnaires, addressed to the lead physician and to the nurse, were emailed. A reminder was sent to non-responders every 10-15 days for a maximum of three times. At that point, if no answer was received, the participant was contacted by phone by an investigator and the questionnaire carried out as a telephonic interview.

Two sessions composed the questionnaire First session asked about Delivery Room (DR) and NICU respiratory support strategies and specific policies adopted for ELGANs. The second session investigated whether there was any area of respiratory support considered as needing improvement in the unit through a local training. Different questions were addressed to physicians and nurses. Physicians were requested to answer on, type of respiratory support provided in the DR, preferred mode of ventilation for invasive and non-invasive respiratory support in NICU, use of volume targeted ventilation, use of techniques of surfactant administration for infants under NIV, such as Intubate-Surfactant-Extubate (INSURE) and Less Invasive Surfactant Administration (LISA) approaches, target $\mathrm{FiO}_{2}$ used to deliver surfactant, and administration of analgesic drugs during both MV and surfactant administration in spontaneously breathing infants. Nurses were requested to answer about lower and upper limit of $\mathrm{SpO}_{2}$ considered safe in their NICU, type and frequency of respiratory parameters (set and measured) and vital signs recorded on the nursing sheet during invasive and non invasive ventilation, use of Silverman and pain assessment scores, titration of analgesic drug during ventilation and number of patient assigned to each nurse in NICU. Both physicians and nurses were asked to address which strategies needed improvement in their units, with the aim of identifying their specific requests.

\section{Results}

In 2013, 514.308 infants were born in Italy. Of them, 1665 were ELGANs $(0.3 \%)$. In our country, there are 113
NICUs dedicated to these extremely preterm babies: two of them do not have a Delivery Room.

We obtained a $100 \%(113 / 113)$ response rate to the questionnaire by both physicians and nurses responsible for each Italian NICU.

\section{Physicians questionnaires \\ Management in the Delivery Room}

Sustained Lung Inflation (SLI) was used to support ELGANs in $74.8 \%$ of centres, while in $19.1 \%$ this strategy was applied upon physician's preference. In 99 (89.2\%) centres, nasal CPAP was used in the DR to assist spontaneously breathing preterm infants with signs of RDS (Table 1).

\section{Invasive Ventilatory support}

Conventional Mechanical Ventilation (CMV) was used as first intention for ELGANs in 72 (63.7\%) NICUs, while $24(21.2 \%)$ preferred HFOV. Seventeen (15.0\%) units used both, indifferently. Among units using preferentially CMV, volume-targeted ventilation (VTV) was commonly chosen during the acute phase of RDS in 31 (27.4\%), while in $51(45.1 \%)$ of them this mode was only set during the weaning phase. Analgesia and sedation during mechanical ventilation were used by $76.1 \%$ of NICUs, being the fentanyl the most used drug (90\%).

\section{Surfactant administration for infants in NIV}

The INSURE technique in spontaneously breathing ELGANs was currently performed in $91.6 \%$ of the centers. Target $\mathrm{FiO}_{2}$ to start the procedure was 0.40 in the majority of cases. LISA technique was utilized only in $19.5 \%$ of NICUs. Analgesic and sedation procedures for the INSURE approach and LISA technique were reported in 59.2 and $43.5 \%$ of centres respectively.

\section{Non-invasive ventilation (NIV)}

Considering non-invasive techniques, the most popular strategy was nCPAP used by all the Italian NICUs, followed by Bilevel CPAP (74.3\%) and High Flow Nasal Cannula (HFNC) (60.2\%). Nasal intermittent positive pressure ventilation (NIPPV) was adopted by $40.0 \%$ of NICUs, but the synchronized mode (SNIPPV) was used only in $8.8 \%$ of them.

\section{Nurses questionnaires Respiratory settings}

Fifty-nine centers (52.2\%) used to titrate oxygen therapy within a range of targeted $\mathrm{SpO}_{2}$ values; however, these were actually recorded only in $8.0 \%$ of nursing charts (Table 2).

Nurses used to report the respiratory settings on their nursing charts in $77.0 \%$ of centers. 
Table 1 Training request, respiratory strategies in the delivery room and NICUs, analgesia from the physicians' questionnaires

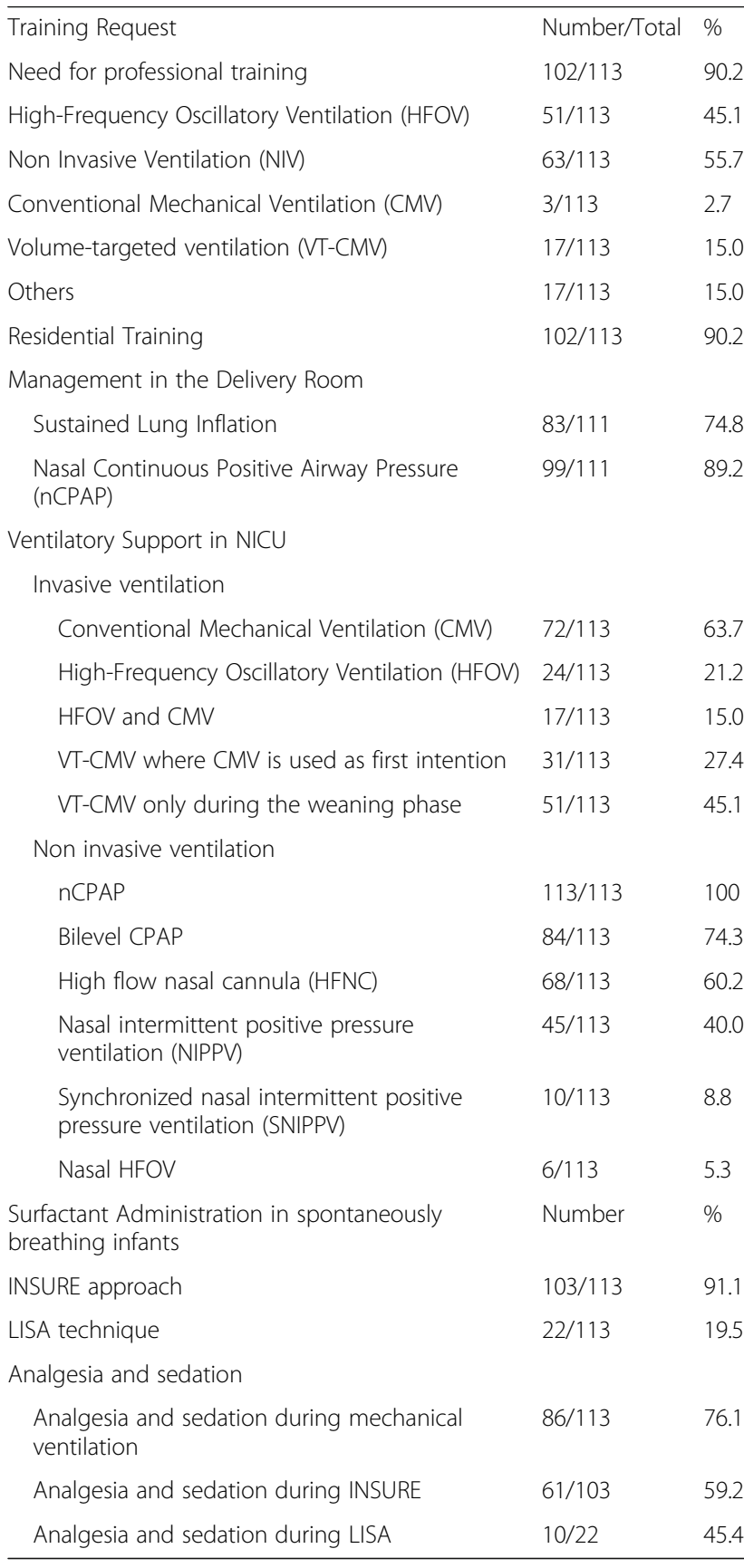

Considering CMV, preset respirator settings $(\mathrm{Ti}, \mathrm{Te}$, PIP, PEEP, etc.) were reported in $87 \%$ of centers, while the measured ones (tidal volume and minute ventilation) in $70.5 \%$.

With regard to $\mathrm{HFOV}$, respiratory set parameters $(\mathrm{Hz}$, MAP, amplitude, etc.) were recorded in $78.3 \%$ of the centers, while measured parameters $\left(\mathrm{DCO}_{2}\right.$ and tidal volume) were recorded in $40.5 \%$.

During NIV, respiratory parameters were reported in $68.1 \%$ of NICUs, while spontaneous respiratory rate and
Table 2 Training requests, respiratory parameters recorded and pain assessment score from the nurses' questionnaires

\begin{tabular}{lll}
\hline & Number/Total & $\%$ \\
\hline Training requests & & \\
Need for professional training & $93 / 113$ & 82.3 \\
High-Frequency Oscillatory Ventilation (HFOV) & $32 / 113$ & 28.3 \\
Non Invasive Ventilation (NIV) & $50 / 113$ & 44.2 \\
Volume-targeted ventilation (VT-CMV) & $4 / 113$ & 3.5 \\
Residential training & $104 / 113$ & 92.0 \\
Target SpO ${ }_{2}$ and respiratory parameters recorded in nursing sheet & \\
Target SpO 2 values & $9 / 113$ & 8.0 \\
Respiratory setting & $87 / 113$ & 77.0 \\
CMV respiratory setting & $74 / 85$ & 87.0 \\
CMV measured parameters & $60 / 85$ & 70.5 \\
HFOV respiratory setting & $29 / 37$ & 78.3 \\
HFOV measured parameters recorded & $15 / 37$ & 40.5 \\
NIV respiratory setting recorded & $77 / 113$ & 68.1 \\
NIV spontaneous respiratory rate recorded & $54 / 113$ & 47.8 \\
Silverman score recorded & $18 / 113$ & 15.9 \\
Pain Assessment Score & & \\
Assessment on infants in CMV & $35 / 85$ & 41.2 \\
Assessment on infants in HFOV & $32 / 37$ & 86.5 \\
Assessment on infants in NIV & $35 / 113$ & 30.9 \\
\hline
\end{tabular}

Silverman score were recorded in 47.8 and $15.9 \%$ of the centers, respectively.

Pain assessment score

Pain scales were assessed in $41.2 \%$ of centers for infants receiving $\mathrm{CMV}$, in $86.5 \%$ of centers for infants receiving HFOV and in $30.9 \%$ of centers for infants receiving non-invasive respiratory support.

\section{Need for updating}

A relevant percentage of physicians (90.2\%) and nurses $(82.3 \%)$ believed that some aspects of the respiratory support strategies used in their NICU needed to be improved, all of them preferring a residential training on these topics. High-Frequency Oscillatory Ventilation (HFOV) and Non-Invasive Ventilation (NIV) were the most quoted topics that both professionals would like to refine.

\section{Discussion}

This survey provides an insight on ventilatory management of ELGANs in Italy from the delivery room through the NICU. According to the literature's evidences, routine use of NCPAP in the delivery room is rooted all over Italy with only $10 \%$ of centers not observing this approach. Indeed, recent systematic reviews and 
meta-analysis [8] indicate that avoiding endotracheal intubation at birth in preterm infants reduces the incidence of BPD. Moreover, recent European RDS guidelines recommend stabilizing breathing babies in the delivery room with CPAP of at least $6 \mathrm{cmH}_{2} \mathrm{O}$ via face mask or nasal prongs [9].

Data on SLI soon after birth for ELGANs in Italy overlap with those reported by Trevisanuto et al. (74.8\% vs 76.6\%) [10]. Sustained inflation maneuver in DR was widely used in Italy in 2013, before its application was no longer recommended due to lack of evidence of efficacy and safety [11]. In this regard, 2015 resuscitation guidelines suggest to consider SLI only in individual clinical circumstance or research settings until more data on efficacy and safety will be available.

To our knowledge, this is the first Italian survey reporting on ventilatory management of ELGANs in NICUs. Dani et al. [12] described ventilatory management in NICU infants of all gestational ages. Our data show that time-controlled, pressure-limited CMV is still the most used ventilatory strategy for these tiny infants. By contrast, only $27.4 \%$ of centers chose the more lung protective VTV during the acute phase of RDS, while $45.1 \%$ of them select this mode during the weaning phase, paradoxically when babies are less exposed to lung injury. This occurs despite the wide literature evidence on VTV efficacy in reducing VILI and improving long-term outcomes $[13,14]$. We speculate that this can be a consequence of a lack of expertise among physicians and not to the availability of too obsolete machines. As reported by Dargaville and Tingay [4], physicians are not commonly accustomed to consider measured ventilatory parameters in order to tailor the ventilator settings to the specific patient's needs, which are essential to assure a "protective" invasive ventilation. This underestimation of measured ventilatory parameters is also reflected by the relatively high percentage of NICU nurses (30\%) not recording these parameters on their nursing charts. This result highlights the need to raise awareness among both physicians and nurses.

HFOV as first intention is less used than CMV among these particularly delicate preterm infants, but there is a great demand for insights on this topic by both physicians and nurses. The recent introduction in the market of hybrid ventilators able to effectively perform both CMV and HFOV may encourage wider use of HFOV.

Among non-invasive respiratory techniques, NCPAP, Bilevel CPAP and HFNC are the most widely used in our country. Surprisingly, only $40 \%$ of centres use NIPPV, despite the emerging evidence that this mode may be superior to NCPAP in preventing extubation failure [15] and treating the acute phase of RDS [16]. Moreover, synchronized NIPPV, that may offer some advantages over NIPPV [17-19], is rarely used probably due to the limited diffusion of ventilators able to deliver it. In general, physicians and nurses of more than $40 \%$ of Italian centers claim the need for upgrading their knowledge on non-invasive ventilation.

One hundred and 3 centres (94\%) use the INSURE approach for extremely preterm infants suffering from mild to moderate RDS treated with NCPAP as primary mode, indicating that this technique is considered as an useful tool to avoid invasive mechanical ventilation. Less invasive surfactant administration (LISA) technique has been more recently introduced in neonatology and therefore less commonly used around the country.

It is somewhat disappointing the observation that infant's pain scales are assessed in less than $50 \%$ of centers during CMV, even if the percentage increases up to 86.5\% during HFOV. Considering that pain management is increasingly recognized as an integral part of effective management of vulnerable babies in the NICU, we believe that analgesic and sedation procedures should be improved in Italian NICUs.

\section{Conclusions}

The results of our study refer to the year 2013 and this certainly represents a limit of our survey, nevertheless they offer the opportunity to focus on the "state of the art" of current practices of neonatal respiratory support for ELGANs in Italian DRs and NICUs. Moreover, they provide information about perceived and not perceived training needs of the medical and nursing staff. Upon these collected data, tailored residential training or courses on ventilatory strategies to be introduced or improved in each unit may represent the preferred way for refining and standardizing ELGANs' respiratory care in our country. This opportunity may be also relevant in consideration that newer machines and ventilatory techniques are made available by the market and they need an optimal staff training to be properly utilized.

\section{Abbreviations \\ BiPAP: Bilevel Positive Airway Pressure; BiPAP: Bi-level positive airway pressure; CMV: Conventional mechanical ventilation; HFNC: High Flow Nasal Cannula; HFNC: High-flow nasal cannula; HFOV: High-frequency oscillatory ventilation; iNO: Inhaled nitric oxide; LISA: Less Invasive Surfactant \\ Administration; MV: Mechanical ventilation; NCPAP: Nasal continuous positive airway pressure; NICU: Neonatal intensive care unit; NIPPV: Nasal intermittent positive pressure ventilation; RDS: Respiratory distress syndrome; SIMV: Synchronized intermittent mandatory ventilation; VTV: Volume Targeted Ventilation}

\author{
Acknowledgements \\ The authors acknowledge all the Neonatal Units respondent to the survey. \\ Funding \\ No external funding was received for this study. \\ Availability of data and materials \\ The datasets used and analyzed during the current study are available from \\ the corresponding author on reasonable request.
}




\section{Authors' contributions}

FP conceived and designed the survey, contributed to data collection, carried out the initial analysis and wrote the first draft of the manuscript. CG designed the survey, collected data and edited the manuscript. GM carried out the data collection and the literature search and reviewed the manuscript. PM edited the survey, contributed in data collection and analysis and edited the manuscript. MLV contributed in study design, carried out the data collection, the literature search and revised the manuscript. CR carried out the data collection, the literature search, helped with translation and edited the manuscript. RP prepared electronic data sheets, carried out data analysis and has given final approval of the version to be published. GV designed the study, coordinated and supervised data collection, critically reviewed the manuscript, and approved the final manuscript as submitted. All authors read and approved the final manuscript.

\section{Ethics approval and consent to participate}

Not applicable.

\section{Consent for publication}

Informed consent was obtained from all individual participants included in the study.

\section{Competing interests}

The authors declare that they have no competing interests.

\section{Publisher's Note}

Springer Nature remains neutral with regard to jurisdictional claims in published maps and institutional affiliations.

\section{Author details}

${ }^{1}$ Division of Neonatology, Ospedale Di Venere, Bari, Italy. ${ }^{2}$ Azienda Ospedaliera Regionale "San Carlo", Potenza, Italy. ${ }^{3}$ Division of Neonatology, Azienda Ospedaliero-Universitaria "Ospedali Riuniti di Foggia", Foggia, Italy. ${ }^{4}$ Department of Clinical Sciences and Community Health, Fondazione IRCCS Cà Granda Ospedale Maggiore Policlinico, Università degli Studi di Milano, Milan, Italy. ${ }^{5}$ Fondazione MBBM - Ospedale San Gerardo Monza, Monza, Italy. ${ }^{6}$ Department of Woman and Child Health and Public Health, Division of Neonatology, Fondazione Policlinico Universitario A. Gemelli IRCCS Università Cattolica del Sacro Cuore, Rome, Italy. ${ }^{7}$ Section of Hygiene, Institute of Public Health - Università Cattolica del Sacro Cuore, Rome, Italy.

\section{Received: 29 November 2018 Accepted: 29 March 2019}

\section{Published online: 11 April 2019}

\section{References}

1. Keszler M, Abubakar KM. Volume Guarantee Ventilation. Clin Perinatol. 2007:34:107-16.

2. Keszler M. State of the art in conventional mechanical ventilation. J Perinatol. 2009;29:262-75.

3. Lista G, Castoldi F, Fontana P, Reali R, Reggiani A, Bianchi S, Compagnoni G. Lung inflammation in preterm infant with respiratory distress syndrome: effects of ventilation with different tidal volumes. Pediatr Pulmonol. 2006:41:357-63.

4. Dargaville PA, Tingay DG. Lung protective ventilation in extremely preterm infants. J Paediatr Child Health. 2012;48(9):740-6.

5. Mehler K, Grimme J, Abele J, Huenseler C, Roth B, Kribs A. Outcome of extremely low gestational age newborns after introduction of a revised protocol to assist preterm infants in their transition to extrauterine life. Acta Paediatr. 2012;101(12):1232-9.

6. Templin L, Grosse C, Andres V, Robert CD, Fayol L, Simeoni U, Boubred F. A quality improvement initiative to reduce the need for mechanical ventilation in extremely low gestational age neonates. Am J Perinatol. 2017;34(8):759-64

7. Sant'Anna GM, Keszler M. Developing a neonatal unit ventilation protocol for the preterm baby. Early Hum Dev. 2012;88:925-9.

8. Fischer $\mathrm{HS}$, Bührer C. Avoiding endotracheal ventilation to prevent bronchopulmonary dysplasia: a meta-analysis. Pediatrics. 2013;132(5):e1351-60.

9. Sweet DG, Carnielli V, Greisen G, Hallman M, Ozek E, Plavka R, et al. European consensus guidelines on the Management of Respiratory Distress Syndrome - 2016 update. Neonatology. 2016;111(2):107-25.

10. Trevisanuto D, Satariano I, Doglioni N, Criscoli G, Cavallin F, Gizzi C, et al. On behalf of neonatal resuscitation study group, Italian Society of Neonatology.
Changes over time in delivery room management of extremely low birth weight infants in Italy. Resuscitation. 2014;85:1072-6.

11. Lista G, Boni L, Scopesi F, Mosca F, Trevisanuto D, Messner H, et al. On behalf of the SLI trial investigators. Sustained lung inflation at birth for preterm infants: a randomized clinical trial. Pediatrics. 2015;135(2):e457-64.

12. Dani C, Bresci C, Lista G, Martano C, Messina F, Migliori C, Vento G. Neonatal respiratory support strategies in the intensive care unit: an Italian survey. Eur J Pediatr. 2013;172:331-6.

13. Wheeler K, Klingenberg C, McCallion N, Morley CJ, Davis PG. Volumetargeted versus pressure-limited ventilation in the neonate. Cochrane Database Syst Rev. 2010;(11):CD003666.

14. Peng W, Zhu H, Shi H, Liu E. Volume-targeted ventilation is more suitable than pressure-limited ventilation for preterm infants: a systematic review and meta-analysis. Arch Dis Child Fetal Neonatal Ed. 2014;99(2):F158-65.

15. Lemyre B, Davis PG, De Paoli AG, Kirpalani H. Nasal intermittent positive pressure ventilation (NIPPV) versus nasal continuous positive airway pressure (NCPAP) for preterm neonates after extubation. Cochrane Database Syst Rev 2014;(9): CD003212.

16. Lemyre B, Laughon M, Bose C, Davis PG. Early nasal intermittent positive pressure ventilation (NIPPV) versus early nasal continuous positive airway pressure (NCPAP) for preterm infants. Cochrane Database Syst Rev. 2016;(4): CD005384.

17. Chang HY, Claure N, D'ugard C, Torres J, Nwajei P, Bancalari E. Effects of synchronization during nasal ventilation in clinically stable preterm infants. Pediatr Res. 2011;69(1):84-9.

18. Gizzi C, Montecchia F, Panetta V, Castellano C, Mariano C, Campelli M, et al. Is synchronised NIPPV more effective than NIPPV and NCPAP in treating apnoea of prematurity (AOP)? A randomised cross-over trial. Arch Dis Child Fetal Neonatal Ed. 2015;100(1):F17-23.

19. Huang L, Mendler MR, Waitz M, Schmid M, Hassan MA, Hummler HD. Effects of synchronization during noninvasive intermittent mandatory ventilation in preterm infants with respiratory distress syndrome immediately after Extubation. Neonatology. 2015;108(2):108-14.

\section{Ready to submit your research? Choose BMC and benefit from:}

- fast, convenient online submission

- thorough peer review by experienced researchers in your field

- rapid publication on acceptance

- support for research data, including large and complex data types

- gold Open Access which fosters wider collaboration and increased citations

- maximum visibility for your research: over $100 \mathrm{M}$ website views per year

At BMC, research is always in progress.

Learn more biomedcentral.com/submissions 